\title{
Coordinated Operation of Wind Turbines and Flywheel Storage for Primary Frequency Control Support
}

\author{
Francisco Díaz-González ${ }^{\mathrm{a}}$, Melanie Hau ${ }^{\mathrm{b}}$, Andreas Sumper ${ }^{\mathrm{a}, \mathrm{c}}$, Oriol Gomis-Bellmunt ${ }^{\mathrm{a}, \mathrm{d}}$ \\ ${ }^{a}$ IREC Catalonia Institute for Energy Research, C. Jardins de les Dones de Negre, 1, Pl. 2a, 08930 Sant Adrià del Besòs, Spain \\ ${ }^{b}$ Fraunhofer Institute for Wind Energy and Energy System Technology (IWES), Königstor 59, 34119 Kassel, Germany \\ ${ }^{c}$ Centre d'Innovació Tecnològica en Convertidors Estàtics i Accionaments (CITCEA-UPC), Departament d'Enginyeria Elèctrica, Universitat \\ Politècnica de Catalunya EU d'Enginyeria Tècnica Industrial de Barcelona, C. Comte d'Urgell, 187, Pl. 2, O8036 Barcelona, Spain \\ ${ }^{d}$ Centre d'Innovació Tecnològica en Convertidors Estàtics i Accionaments (CITCEA-UPC), Departament d'Enginyeria Elèctrica, Universitat \\ Politècnica de Catalunya ETS d'Enginyeria Industrial de Barcelona, Avinguda Diagonal, 647, Pl. 2, 08028 Barcelona, Spain
}

\begin{abstract}
This work assesses the participation of wind power plants in primary frequency control support. To participate in frequency control-related tasks, the wind power plants have to maintain a certain level of power reserves. In this article, the wind power plant is equipped with a flywheel-based storage system to fulfil the power reserve requirements set by the network operator. The article focuses on two main aspects: the definition of the control strategy to derate the wind turbines to provide a part of the required power reserves; and the coordinated regulation of the power reserves of the wind turbines and the flywheels while participating in primary frequency control. This coordinated regulation enables the wind power plant to maintain the net level of power reserves set by the network operator while alleviating the need of deloading the wind turbines. The performance of the proposed control schemes are shown by simulation.

Keywords: Primary Frequency Control, Wind Power Plants, Flywheel Storage, Grid Codes, deloading methods.

\section{Introduction}

The increasing importance of wind power plants (WPPs) in the electrical network affects system operation due to the stochastic nature of wind power [1]. For that reason, more stringent requirements are gradually developed by system operators for the grid integration of WPPs $[2,3,4]$. These regulations require WPPs to behave in several aspects similar to conventional synchronized generating units. Among other requirements, the participation of WPPs in system frequency control-related tasks is set (as indicated, for instance, by the Irish operator [3]).

Wind turbines (WTs) are capable of providing system frequency control support $[5,6,7,8,9]$. In [5] an analy-

Email address: fdiazg@irec.cat. Tel. +34 933562615

Fax. $\quad+34933563802$ Corresponding Author

(Francisco Díaz-González)

sis on the effects of the displacement of the conventional generating units in a power system with high penetration of WPPs is proposed. Results highlight the necessity of WPPs to participate in frequency control as the synchronized inertia of the system is lowered by the decoupling of the rotor inertia of the wind turbines by fast controlled power electronics. Frequency stability may be compromised with reduced levels of synchronized inertia since high rates of change of frequency can be registered.

For ensuring the constancy and stability of the frequency of the electrical network, a certain level of active power reserves is required. These reserves are continuously regulated to match the power consumption and generation in the network, but also in presence of power disturbances such as sudden trips of generating units in order to participate in frequency control. Wind turbines have to be operated not extracting the maximum available power
\end{abstract}




\begin{tabular}{|c|c|c|c|}
\hline \multicolumn{4}{|c|}{ Nomenclature } \\
\hline \multicolumn{4}{|c|}{ Parameters } \\
\hline$A$ & Area covered by WT blades, $\left(\mathrm{m}^{2}\right)$ & $P_{o p t_{d e l}}$ & Output of a WT while being deloaded, (MW) \\
\hline$C_{p_{\text {opt }}}$ & Optimal Betz coefficient for WT, (-) & $P_{\text {storage }}^{*}$ & Power reserve that flywheels can handle, (MW) \\
\hline$H$ & Inertia constant for conventional generation, (s) & $P_{w t}$ & Power generated by WTs measured at PCC, (MW) \\
\hline$J_{f w}$ & Inertia of a flywheel unit, $\left(\mathrm{kg} \cdot \mathrm{m}^{2}\right)$ & $P_{w t_{\max }}$ & Max. power WPP can extract from wind, (MW) \\
\hline$K_{C p}(\cdot)$ & Optimal torque coeficient for WT, $\left(\mathrm{Ws}^{2} / \mathrm{rad}^{2}\right)$ & $T_{e}^{*}$ & WT electrical torque reference, $(\mathrm{Nm})$ \\
\hline$n_{f w}$ & Number of flywheel units, (-) & $T_{o p t_{d e l}}$ & WT torque while being deloaded, $(\mathrm{Nm})$ \\
\hline$R$ & Primary control droop for synchronous gen., (-) & $v_{w_{\min }}$ & Wind speed for which the WT achieves its rated \\
\hline$R_{w p p}$ & Primary frequency control droop for WPP, (-) & & speed while maintaining a power margin $x,(\mathrm{~m} / \mathrm{s})$ \\
\hline$T_{\text {loss }}$ & Flywheel torque losses, (Nm) & $x$ & Power margin, (-) \\
\hline$v_{w}$ & Wind speed, $(\mathrm{m} / \mathrm{s})$ & $x_{\text {cap }+}$ & Magnitude $P_{c a p+}$ in per unit of the maximum ava- \\
\hline$v_{w_{\text {rated }}}$ & Rated wind speed for WTs, $(\mathrm{m} / \mathrm{s})$ & & ilable power that WTs can capture from wind, (-) \\
\hline$x_{s d}^{*}$ & Steady state power margin ref. for the WPP, (-) & $x_{\text {cap- }}$ & Magnitude $P_{c a p-}$ in per unit of the maximum ava- \\
\hline$\delta$ & Time constant, (s) & & ilable power that WTs can capture from wind, (-) \\
\hline$\omega_{\min }$ & Minimum operating speed for flywheels, (rad/s) & $x_{w t}^{*}$ & Total power margin reference for WTs, (-) \\
\hline$\omega_{\max }$ & Maximum operating speed for flywheels, $(\mathrm{rad} / \mathrm{s})$ & $x_{w t_{s d}}^{*}$ & Power margin reference in steady state, (-) \\
\hline \multirow[t]{2}{*}{$\omega_{t_{\text {rated }}}$} & Rated speed for WTs, $(\mathrm{rad} / \mathrm{s})$ & $\beta$ & Pitch angle, (degrees) \\
\hline & & $\beta_{\max }$ & Pitch angle for power margin $x$ at rated wind \\
\hline \multicolumn{2}{|c|}{ Variables } & & speed, (degrees) \\
\hline$C_{p_{d e l}}$ & Betz coefficient for a WT while being deloaded, (-) & $\Delta f$ & Frequency deviation, (-) \\
\hline & Electrical frequency of the network, $(\mathrm{Hz})$ & $\Delta t\left(f_{e}\right)$ & Time length that flywheels would be required to \\
\hline$P_{\text {cap }+}$ & Power that flywheels can inject for $30 \mathrm{~min}$, (MW) & & inject or absorb power continuously, (s) \\
\hline$P_{\text {cap- }}$ & Power that flywheels can absorb for $30 \mathrm{~min},(\mathrm{MW})$ & $\Delta x$ & Power margin interval, (-) \\
\hline$P_{\text {load }}$ & Network load demand, (MW) & $\Delta x_{w t}$ & Power margin variation required to WTs, (-) \\
\hline$P_{l o s s_{w t}}$ & Power losses in the WPP collection grid, (MW) & $\omega_{f w}$ & Flywheel speed, (rad/s) \\
\hline$P_{\text {opt }}$ & Max. power WTs can extract from wind, (MW) & $\omega_{t}$ & Turbine speed, (rad/s) \\
\hline
\end{tabular}

from the wind but maintaining a certain power margin in order to participate in primary frequency control.

But maintaining a power margin is a major drawback from the point of view of the operators of WPPs, as they are losing revenues from not selling up to $10 \%$ of the available power that can be captured from wind in normal and continuous operation. In addition, the primary frequency support WPPs can provide, depends on the wind speed and the control techniques applied for regulating the power margin.

From the above mentioned considerations, it could be interesting to the owner of a WPP to connect an energy storage system in the point of common coupling of the generating facility with the external grid. In this case the wind turbines could be operated extracting the maximum available power from the wind. The energy storage system would provide the required power reserves for the participation of the WPP in primary frequency control therefore. The economic viability of the project would be determined by a cost-benefit analysis considering the cost of the storage system against the alternative of operating the wind turbines in a deloaded mode in a continuous basis.

Of course, from the point of view of the network operation, the inclusion of an energy storage system in the point of connection of a generation facility could not be the better allocation. The installation of the storage facility near the network loads in order to reduce transmission losses could be preferable. However, it is also interesting to study the allocation of the storage system in the point of connection of a WPP for several reasons: i) The exploitation of the high-ramp power rates and short time responses of an adequate storage technology could lead to a great system primary frequency support from the point of common coupling of the wind facility to the grid; ii) To install a storage facility could help the WPP to fulfil 
the gradually increasing requirements of the grid codes regarding the grid integration of renewable-based power plants [1].

Several energy storage devices suitable for frequency control - related tasks can be found. Among them, the literature considers the application of large scale storage systems like pumped-hydro, compressed-air and hydrogen-based systems. Also, it is worth noting that batteries, flow batteries and those storage devices with very high ramp power rates and short time responses like Superconducting Magnetic Energy Storage (SMES) and flywheels are specially well-suited for this application [1]. Remarkable characteristics of flywheels are their very high ramp power rates, high cyclability and energy efficiency (around 90\% [10, 11]). On the other hand, standing losses are non-negligible. In fact, self-discharge rates are about $20 \%$ of the stored capacity per hour [12].

This work considers the inclusion of a flywheel-based storage plant in the point of common coupling (PCC) of a WPP with the external grid. The flywheels are considered to be part of the WPP and provide part of the power reserves indicated by the system operator to the WPP. This way, the WPP participates in primary frequency control. Wind turbines are required to operate to some extent in a deloaded mode depending on the level of power reserves of the flywheels, i.e. depending on their State of Charge (SoC). Thus, the required power reserves by the system operator to the wind facility can be computed by the sum of the power reserves of the flywheels and the power reserves provided by the wind turbines. The latter can be deduced from the capability of the wind turbines to increase their generation level up to the maximum available power that can be extracted from the wind. Conceptually, the scope of the work responds to Figure 1.

Two contributions from the present work can be pointed out:

- The design of the central control system of the WPP and the local controllers of the wind turbines and the flywheels. These control systems are in charge of regulating the power reserves maintained by the wind turbines and the flywheels under network disturbances and also in normal operating conditions. In case of a network disturbance, i.e. of a system frequency deviation from its set-point, the power reserves of the wind turbines and the flywheels are im-

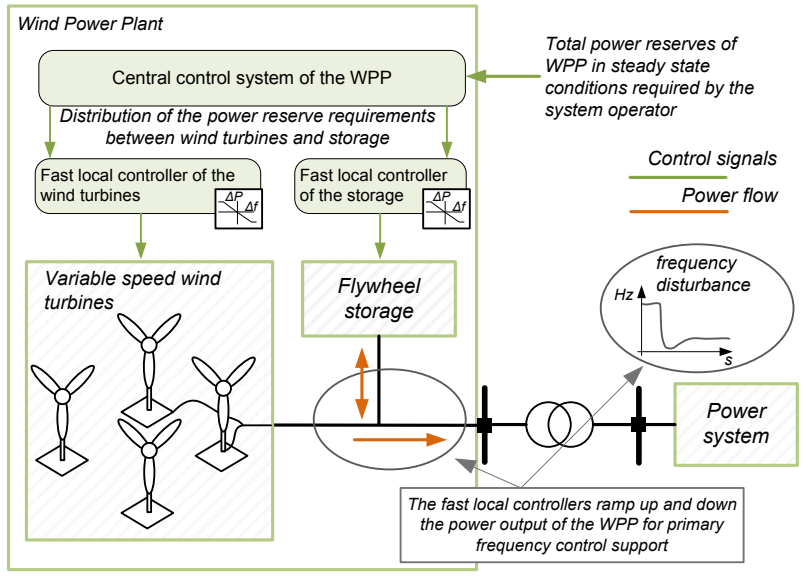

Figure 1: Conceptual diagram of the scope of the work

mediately activated by their local controllers. This activation though, is supervised by the central control system of the WPP, and this is the main contribution of the article.

- The determination of the control method to allow the wind turbines to maintain a certain power margin from the maximum available power that can be extracted from the wind. This control method is included in the local controller of the wind turbines. It is adopted and adapted from that presented in [13]. This is intended as a minor contribution of the paper.

\section{Proposed control schemes for the wind power plant}

In regard of the main contributions of the article, this section deals with the presentation of control techniques for enabling a wind turbine to operate maintaining a power margin from the maximum available power that can be extracted from the wind. Also, the proposed central control system of the WPP to manage the power reserves of the wind turbines and the flywheels is detailed.

\subsection{Deloaded operation of wind turbines}

\subsubsection{State of the art}

Conventionally, wind turbines are operated at maximum aerodynamic efficiency to maximize power generation. At partial-load region, the turbine speed is controlled 
by the regulation of the aerodynamic torque, leading the so-called optimal torque (or power) - omega curve [14]. Applying this approach, the optimal aerodynamic power is computed as

$$
P_{o p t}^{*}=K_{C p}(\beta) \cdot \omega_{t}^{2},
$$

where $\omega_{t}$ is the turbine speed and $K_{C p}$ is the so-called optimal aerodynamic torque coefficient, which depends on the aerodynamics of the turbine and the pitch angle $\beta$. This pitch angle is kept constant at partial load region, but at full-load region, it is continously regulated so as the rated speed of the turbine is not overcome.

This control strategy cannot be applied for derating wind turbines. Basically, there are two options for enabling a wind turbine to maintain a certain level of power reserves and thus to participate in frequency controlrelated tasks. These options are overspeeding and pitching techniques of wind turbines for deloaded operation. Both are based on operating the wind turbines not extracting the maximum available power from wind. Overspeeding techniques are carried out applying the so-called deloaded optimum torque (or power) - omega curves $T-\omega$ $[15,16,17,18,19]$. These curves impose operating points out of the optimum $T-\omega$ curve that allows extracting the maximum available power from the wind. The deloaded optimum $T-\omega$ curves are defined up to the rated speed of the turbine as presented in Figure 2. As can be noted, following these operating curves, the rated speed of the turbine is reached for wind speeds much lower than nominal.

As an example, following the deloaded optimum $T-\omega$ curve for the power margin $x=0.20 \mathrm{pu}$, the wind turbine achieves its rated rotational speed for wind speeds around $7.5 \mathrm{~m} / \mathrm{s}$. Note that, at maximum efficiency, the rated wind speed for the turbine is around $10.1 \mathrm{~m} / \mathrm{s}$. Once the wind turbine reaches its rated speed, combined regulations between the electrical torque and the pitch angle are needed in order to maintain the desired power margin level. Otherwise the wind turbine would overcome its speed ratings.

In the literature different approaches to the configuration of the deloaded operating curves can be found. In [18], the implementation of a droop characteristic in the deloaded $T-\omega$, between $99 \%$ and $100 \%$ of the rated speed of the turbine is proposed. The end point of this line corresponds to $100 \%$ of the rated speed of the turbine. At

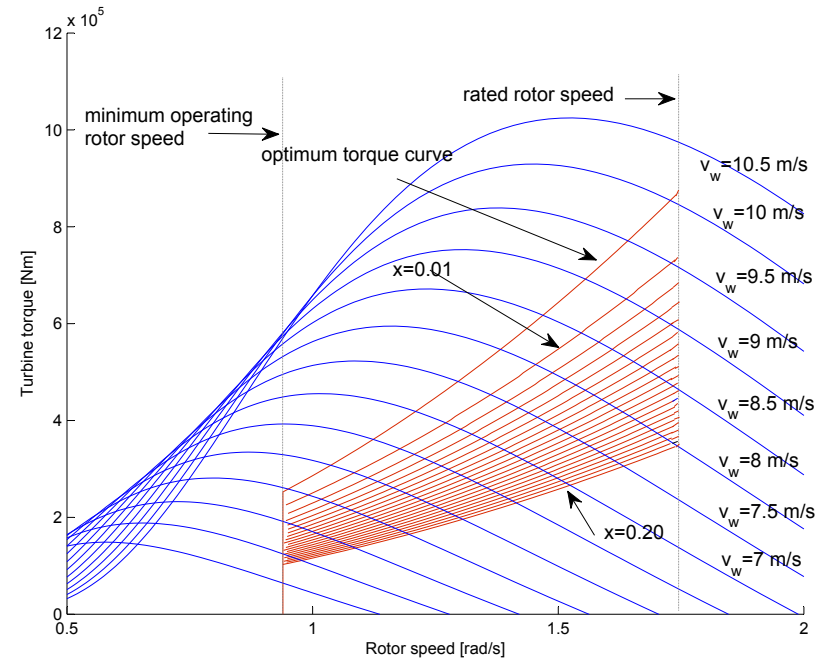

Figure 2: Deloaded optimum $T-\omega$ curves for a DFIG-based wind turbine of $1.5 \mathrm{MW}$ of rated power for power margins up to $20 \%$. Rated wind speed $10.1 \mathrm{~m} / \mathrm{s}$

this point, the electrical torque reference is set as that of maintaining the desired power margin with respect to the rated power of the turbine. This approach cannot ensure the required power margin while operating at wind speeds below but near rated, i.e. while operating following this droop characteristic between $99 \%$ and $100 \%$ of the rated speed.

In the literature different approaches to the definition of the deloaded operating curves can be found. In [13] a strategy to ensure the required power margin at all operating ranges of a wind turbine is proposed. For wind speeds near and above nominal, when the rated rotor speed is reached, a three dimensional look-up-table which inputs the pitch angle and the required power margin is applied. The look-up-table provides the electrical power setpoint of the wind turbine. For the computation of this three dimensional look-up-table, and to the best of the knowledge of the authors of the present work, the power margin is defined in this article from the ratio between the developed electrical power and the rated power of the turbine.

In the present chapter, the power margin $x$ (in pu) is defined from the ratio between the generated electrical power $P_{o p t_{d e l}}$ and the maximum power that can be extracted from the wind. Mathematically, this can be for- 
mulated as

$$
(1-x)=\left\{\begin{array}{lll}
\frac{P_{\text {opt del }}}{P_{\text {opt }}} & \text { if } & v_{w} \leq v_{w_{\text {rated }}} \\
P_{\text {opt del }} & \text { if } & v_{w}>v_{w_{\text {rated }}} \\
\hline P_{\text {rated }} & \text { r }
\end{array}\right.
$$

\subsubsection{Proposed control method}

The present article proposes an strategy for ensuring the required power margin for the full operating range of a wind turbine. Overspeeding techniques are implemented for rotor speeds below the rated speed. In this operating range, the wind turbine is governed by the deloaded $T-\omega$ curves of Figure 2. Pitch angle is zero in this operating range. Once the rated speed of the turbine has been reached, the electrical torque reference is determined by a second look-up-table. As in [13], this look-up-table inputs the pitch angle, which is regulated so that the rated rotor speed of the turbine is not overcome, and the required power margin. As a difference with [13], the output of the look up table is not the electrical power setpoint, but the electrical torque reference to the generator. Moreover, this magnitude is determined from the definition of the power margin presented in (2).

The computation of this second look-up-table is presented as follows. Given a power margin $x$, the wind turbine achieves its rated speed at a wind speed below rated $v_{w_{\text {min }}}$. From this wind speed on (up to the rated wind speed for the wind turbine $\left.v_{w_{\text {rated }}}\right)$, the required power margin is achieved with a proper combination of the pitch angle $\beta$ and the electrical torque. Mathematically, the complementary of the power margin $(1-x)$ can be expressed as

$$
\begin{aligned}
\frac{P_{o p t_{\text {del }}}}{P_{\text {opt }}} & =\frac{0.5 \rho A v_{w}^{3} C_{p_{\text {del }}}\left(v_{w}, \omega_{t_{\text {rated }}}, \beta\right)}{0.5 \rho A v_{w}^{3} C_{p_{\text {opt }}}\left(v_{w}, \omega_{t_{\text {opt }}}, 0\right)} \\
& =\frac{C_{p_{\text {del }}}\left(v_{w}, \omega_{t_{\text {rated }}}, \beta\right)}{C_{p_{\text {opt }}}\left(v_{w}, \omega_{t_{\text {opt }}}, 0\right)}=(1-x),
\end{aligned}
$$

where $v_{w} \epsilon\left[v_{w_{\text {lim }}}, v_{w_{\text {rated }}}\right]$ and there is one minimum wind speed $v_{w_{\text {lim }}}$ for each power margin $x$. Therefore, solving this equation for each wind speed $v_{w}$ and power margin $x$, the required pitch angle for each case can be calculated. Then, for each combination $\left(v_{w}, \beta\right)$, it is possible to find the required deloaded optimum torque as

$$
T_{o p t_{d e l}}=\frac{P_{o p t_{d e l}}}{\omega_{t_{\text {rated }}}} .
$$

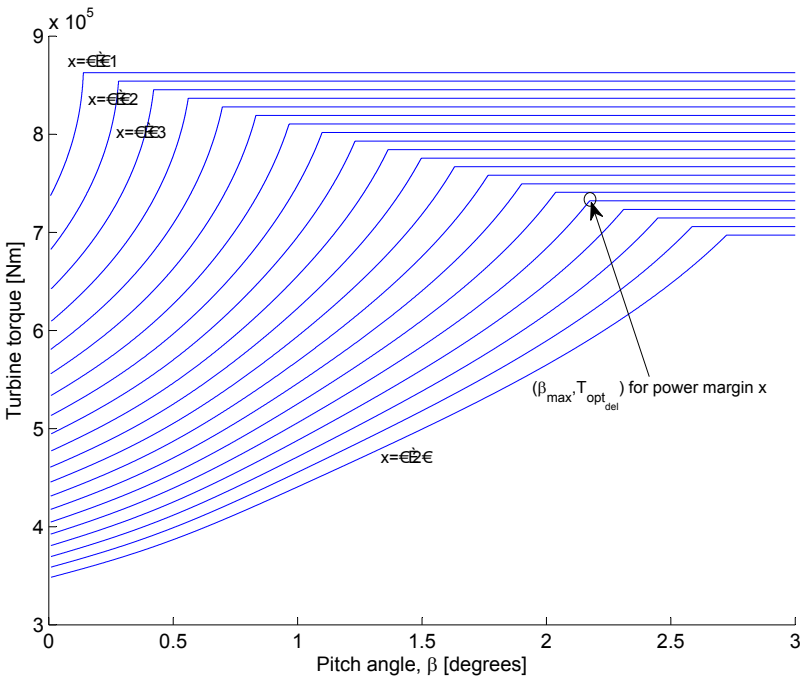

Figure 3: Proposed torque curves depending on the pitch angle and the power margin $x$

Applying this procedure, the torque curves of Figure 3 can be drawn.

Note that for each power margin $x$, there is a pitch angle that corresponds to the deloaded operating point at rated wind speed, denoted as $\beta_{\max }$. From this pitch angle on, the electrical torque for the required deloaded operation becomes constant, as it is simply calculated as

$$
T_{o p t_{\text {delB } \beta>\max }}=\frac{P_{\text {rated }}(1-x)}{\omega_{t_{\text {rated }}}} .
$$

The proposed strategy for the determination of the torque reference at all operating ranges leads to the control scheme for deloaded operation of the wind turbine of Figure 4.

As presented, the control system inputs five signals: the frequency deviation $\Delta f$ from its nominal value, the power margin reference in steady state conditions $x_{w t \_s d}^{*}$, the rated rotational speed of the turbine $\omega_{t \text { rated }}$, and the measurement of the rotational speed of the turbine $\omega_{t}$ and the pitch angle $\beta$.

Given a frequency deviation $\Delta f$, the power / frequency droop characteristic for the primary frequency control outputs an increment or decrement in the desired power margin of the wind turbine in per unit values $\Delta x$. Then, this variation is added to the required steady state power 


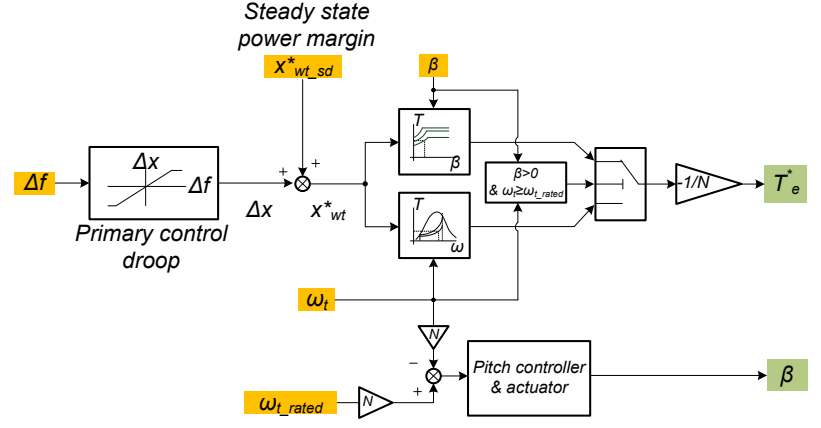

Figure 4: Control scheme for deloaded operation of a variable speed wind turbine for its participation in primary frequency control

margin $x_{w t_{s} s d}^{*}$, given the total power margin reference $x_{w t}^{*}$. The steady state power margin reference refers to the power margin to be maintained in normal operating conditions of the grid, i.e. in case of having a steady frequency level of 50 or $60 \mathrm{~Hz}$, depending on the network. This control signal can be provided by the network operator.

Considering that the rotational speed of the wind turbine is lower than the rated, the electrical torque reference $T_{e}^{*}$ is obtained accessing to the $T-\omega$ curve (Figure 2 ). This torque reference is sent to the low level control algorithm of the rotor-side power converter of the wind turbine, i.e. the inner current control loop for the converter.

Once the rated speed of the wind turbine is reached, the regulation of the pitch angle comes into play. A conventional speed controller drives the pitch actuator. This way the speed of the turbine is not exceeded. In this operating range, the torque reference for the generator is obtained accessing to the $T-\beta$ curves of Figure 3 . It is worth noting that the electrical torque reference varies according to the slow dynamics of the pitch controller in this operating range.

The pitch control system includes a PI controller. The tuning of this lineal controller has been carried out so that no greater gradients than \pm 10 degrees per second in the pitch angle are reached. Also, the controller leads a second order type temporal response on a step-profiled reference, with a damping around 0.6-0.7. The maximum pitch angle is limited to 30 degrees.

\subsection{Management of the power reserves of the wind tur- bines and the flywheels for frequency control support}

The central control system of the WPP determines the power reserves that the wind turbines have to provide in steady state conditions, i.e. while experiencing an steady network frequency of 50 or $60 \mathrm{~Hz}$, depending on the network, and taking into account the power reserves that the flywheels are capable of providing. Since a part of the total power reserves required to the overall power plant is provided by the flywheels, the need of deloading the wind turbines so that they can maintain a certain power margin from the maximum available power they can extract from the wind is alleviating. In fact, the regulation of the power margin of the wind turbines is carried out just to handle the power margin that the storage facility cannot satisfy. The central control system does not govern the ramping up and down of the power of the wind turbines and the flywheels in the event of a frequency deviation. The fast local controllers of these elements are responsible of doing that instead.

The central control scheme of the overall power plant is presented in Figure 5, where it is also depicted the local control system of the flywheels and the wind turbines.

As can be noted, the central control system of the WPP receives four input signals: the steady state power margin reference for the WPP (considering the wind turbines and the flywheels) $x_{s d}^{*}$, which is provided by the network operator; the total power margin reference for the wind turbines $x_{w t}^{*}$; the power output of the wind turbines at the point of common coupling of the WPP with the network $P_{w t}$; the rotational speed of the flywheels $\omega_{f w}$; and the electrical frequency of the network $f_{e}$. It is considered that all flywheel units rotate at the same speed as they receive the same control references.

From these inputs, the central controller provides five output signals: the steady state power margin reference for the wind turbines $x_{w t_{-} s d}^{*}$, as well as the signals $P_{c a p+}$, $P_{\text {cap- }}, x_{\text {cap }+}$ and $x_{\text {cap- }}$. These four output signals are needed to inform the local controllers of the wind turbines about the power margin that the flywheels can handle and thus, to limit their fast power output ramping up and down in the event of a frequency deviation.

The action of the central control system of the WPP should be so that it does not counteract with the fast control actions of the local controllers. Fast control actions of 

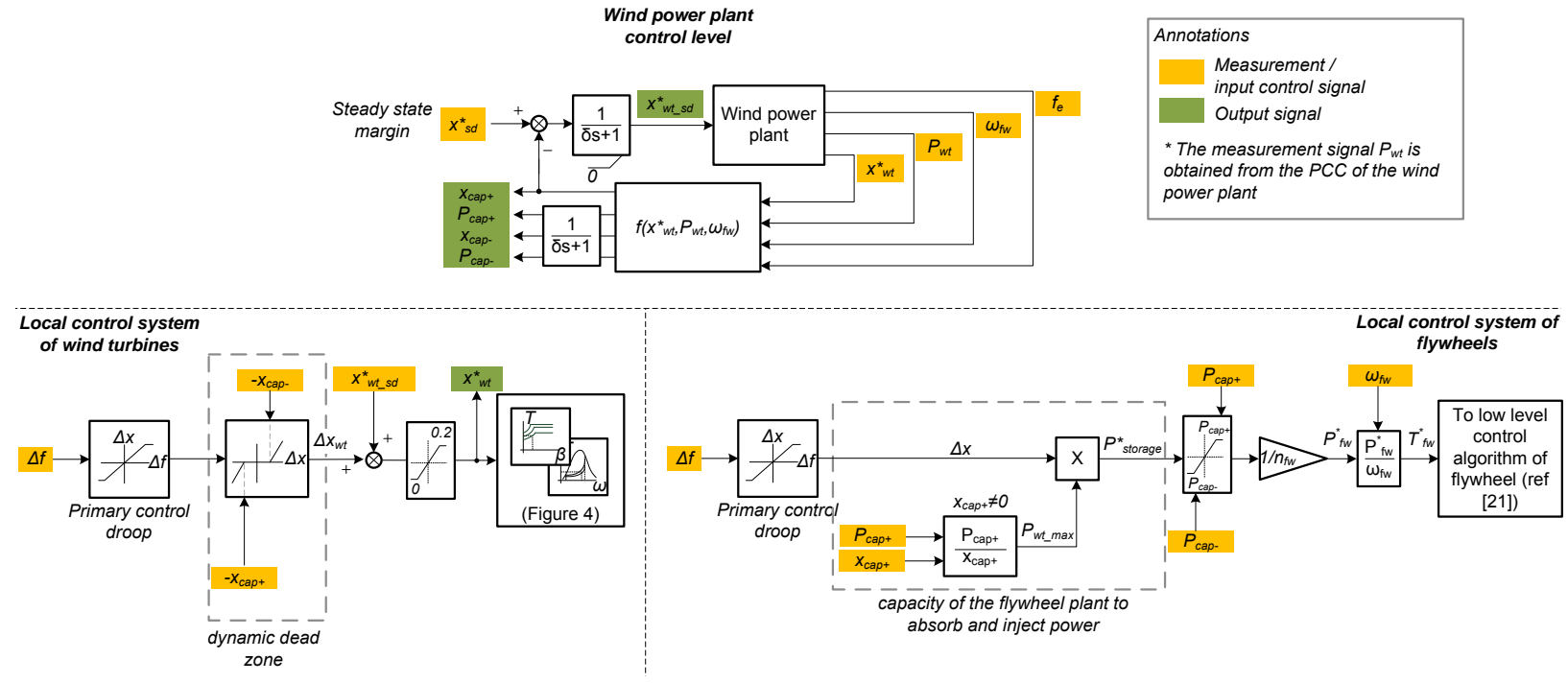

Figure 5: Central control system and local controllers of the wind turbines and the flywheels

the central control system may affect the stability of the WPP as they would compete with the fast actuation of the local controllers of the flywheels and wind turbines. For that reason, the outputs of the central control system are affected by a first order type filter with a time constant of $\delta=5$ seconds. This time constant is chosen taking into account that the time constant of the pitch actuator is in the order of 2 seconds, and the time constant of the response of the storage units are in the order of milliseconds.

Following contents detail the processes carried out by the central control system to provide the previously mentioned output signals.

As it can be noted in Figure 5, the input signals $P_{w t}, x_{w t}^{*}, \omega_{f w}$ and $f_{e}$ serve to compute the function $f\left(P_{w t}, x_{w t}^{*}, \omega_{f w}, f_{e}\right)$. This function determines the capacity of the flywheels to continuously inject or absorb power for up to 30 minutes. This is the period of time indicated in the ENTSO-E's recommendations [4] for the definition of the processes involving primary frequency control in the event of a frequency deviation.

The power (in MW) that the flywheels can continuously absorb for up to 30 minutes is denoted as $P_{\text {cap- }}$. The expression of this value in per unit of the maximum available power that the wind turbines can capture from wind is denoted as $x_{c a p-}$. Similarly, the power (in MW) that the flywheels can inject continuously for up to 30 minutes is named $P_{c a p+}$, and in per unit $x_{c a p+}$. The signals $P_{c a p+}$ and $P_{\text {cap- }}$ are computed as

$P_{\text {cap }}=\frac{n_{f w}}{2}\left(\frac{J_{f w}\left(\omega_{f w}^{2}-\omega_{\min }^{2}\right)-T_{\text {loss }}\left(\omega_{f w}-\omega_{\min }\right) \Delta t\left(f_{e}\right)}{\Delta t\left(f_{e}\right)}\right)$,
$P_{\text {cap }-}=\frac{n_{f w}}{2}\left(\frac{J_{f w}\left(\omega_{f w}^{2}-\omega_{\max }^{2}\right)-T_{\text {loss }}\left(\omega_{f w}-\omega_{\max }\right) \Delta t\left(f_{e}\right)}{\Delta t\left(f_{e}\right)}\right)$,

where $J_{f w}$ is the inertia of a flywheel unit in $\mathrm{kgm}^{2}, \omega_{f w}$ is the speed in rad/s, $\omega_{\min }$ and $\omega_{\max }$ are the operating limits, $T_{\text {loss }}$ is the torque losses (which is almost constant for high-tech flywheels), $n_{f w}$ is the number of flywheel units of the storage plant and $\Delta t\left(f_{e}\right)$ is the time in seconds that the flywheels would be required to inject or absorb power continuously. This value is 30 minutes in normal operating conditions, but it also represents the remaining time that the flywheels must exchange power from the event of a system frequency deviation, so that is why this is expressed as a function of the input signal $f_{e}$, the electrical frequency of the network.

To compute $x_{c a p+}$ and $x_{c a p-}$, it is necessary to estimate the maximum power that wind turbines, as a global, could capture from wind at maximum efficiency, $P_{w t+\max }$ 
(in MW). This is carried out from the measurement of the power generated by the wind turbines at the point of common coupling of the WPP with the external grid and their total power margin reference $x_{w t}^{*}$,

$$
P_{w t \_ \text {max }}=\frac{P_{w t}+P_{\text {loss }_{w t}}}{1-x_{w t}^{*}} .
$$

To compute $P_{w t \_m a x}$, it is necessary to estimate the electrical power losses in the internal grid of the WPP (i.e, cables, power transformers, etc.) that transfers the power of the wind turbines to the point of common coupling with the external network. The power losses are represented by the magnitude $P_{l o s s_{w t}}$. It is assumed, as an approximation, that its value is a percentage of the power measured in the point of common coupling with the external grid, e.g. of about $3 \%$.

The ratio between $P_{c a p+}$ and $P_{w t \text { max }}$ leads $x_{c a p+}$,

$$
x_{\text {cap }+}=\frac{P_{\text {cap }+}}{P_{\text {wt_max }}} \text {. }
$$

Analogously,

$$
x_{\text {cap }-}=\frac{P_{\text {cap }-}}{P_{\text {wt_max }}} .
$$

The subtraction between the steady state power margin reference of the WPP $x_{s d}^{*}$ and the power margin that the flywheels can handle $x_{\text {cap }}$ is the power margin that the wind turbines have to provide in steady state,

$$
x_{w t_{-} s d}^{*}=x_{s d}^{*}-x_{c a p+} .
$$

It is important to note that $x_{w t_{-} s d}^{*}$ is bounded to $0 \%$ for consistency. Negative values of $x_{w t_{-} s d}^{*}$ would not have sense.

As previously noted, the outputs of the central control system $P_{c a p+}, x_{c a p+}, P_{c a p-}$ and $x_{c a p-}$ are used by the local controllers of the wind turbines and the flywheels to limit the ramping up and down of the power injected into the grid by these elements in the event of a frequency deviation (Figure 5). The local controllers are equipped with a primary control droop which translates the detected frequency deviation to a certain decrement (or increment) in the total power margin reference.

Considering a frequency deviation, the WPP is required to ramp up or down its power injection into the grid incrementing or decrementing the total power margin $\Delta x$. From the point of view of the flywheels, this means to absorb or inject power respectively. In any case, the fraction of the total power margin increment or decrement (expressed in MW) set by the primary control droop that the flywheels can handle is

$$
P_{\text {storage }}^{*}=\Delta x \frac{P_{c a p+}}{x_{\text {cap }+}}=\Delta x \frac{P_{\text {cap }-}}{x_{\text {cap }-}}=\Delta x \cdot P_{w t \text { max }} .
$$

As shown in Figure 5, $P_{\text {storage }}^{*}$ is bounded by the power capacity of the flywheels $P_{c a p+}$ and $P_{c a p-}$. Then, the torque reference of each flywheel unit is computed by dividing the above-computed power reference by the rotating speed $\omega_{f w}$ and the number of flywheel units $n_{f w}$.

In the event of a frequency deviation, the primary control droop of the local control system of the wind turbines output the power margin increment $\Delta x$, as the local control system of the storage facility does. However, the local control systems of the wind turbines apply a dynamic dead zone to the signal $\Delta x$, in which the limits of the dead zone are $x_{\text {cap }+}$ and $x_{\text {cap }-}$. This block outputs zero for inputs within the dead zone. Also, it offsets inputs signals by either the negative or positive limits of the dead zone when outside of it. The output of this dynamic dead zone is the actual power margin increment required to the wind turbines $\Delta x_{w t}$. For instance, for an input $\Delta x=0.07$, and $-x_{\text {cap }-}=0.05, \Delta x_{w t}$ results $\Delta x_{w t}=0.07-0.05=0.02$. By applying this strategy, the regulation of the power margin of the wind turbines comes into play just to handle the power margin increment that the storage facility cannot satisfy.

Once the power margin increment of the wind turbines is obtained, it is added to the steady state power margin set by the central control system of the WPP. The obtained power margin set point $x_{w t}^{*}$ is then transmitted to the deloaded optimum torque omega curves of the wind turbines (see Figure 5) in order to develop the adequate electrical torque to fulfill the power margin requirements.

\section{Simulation results}

This section evaluates the performance of the previously proposed control systems for wind turbines and for a WPP equipped with energy storage devices for enabling their participation in primary frequency control. Firstly, the network topology is presented. Secondly, simulation results regarding the regulation of the deloading level of 
wind turbines are presented. Finally, the proposed strategy for the coordinated regulation of the power reserves of the wind turbines and the flywheels is evaluated.

\subsection{Network topology and configuration}

In order to analyse the effect of the active power regulation of wind facilities for primary frequency control, a simple power system is proposed. Figure 6 shows the network topology. The network comprises a non-reheat steam turbine-based conventional power plant, a WPP and a load. The WPP is equipped with a flywheel-based storage facility.

The model of the conventional generating unit includes a third order type model of a synchronous generator, coupled to a non-reheat steam turbine. The electrical model of the generator is detailed extensively in [20], while the model of the steam turbine is explained in [21]. The power generation of the steam turbine is governed by a primary controller as detailed also in [21].

The model of the DFIG-based wind turbines including the electrical and mechanical models, as well as the low level control algorithms of the power converters are fully explained in [22].

Regarding the storage plant, it is worth noting that flywheels are commonly made up of a permanent magnet synchronous machine, mechanically coupled to a rotating disk. The power exchange with the external grid is through a set of back-to-back power converters. The model of the flywheel unit as well as the low level control algorithm of its power converters can be found in [23].

The present work considers a storage plant comprised by several flywheel units in parallel so that it can achieve the required power and energy capacity for participating in primary frequency control. High-speed flywheels commonly regulate hundreds of kilowatts for a few minutes. Therefore, it is needed to dispose several flywheels to regulate tens of megawatts for up to 30 minutes.

According to the Irish network operators EirGrid and Soni, on their publication "All Island TSO Facilitation of Renewables Studies" [24], the Irish network has set the highest binding electricity target in the EU from renewable sources by 2020 . In particular, $40 \%$ of electricity to come from renewables has been accorded. Some of the assumptions made in this study from the Irish network operators will be used in the current work for defining a realistic network with high penetration of wind power.
In the above mentioned work [24], the so-called "operational metric 1" has been defined. This magnitude defines the ratio of wind generation plus import and system load plus export. It is intended as the "inertialess penetration". Upper levels of this ratio than $60-80 \%$ are intended to be only technically viable with major adaptations of the power system. These adaptations refer, among others, to the threshold levels of the rate of change of frequency for the relays at distribution level of more than the actual level of $\pm 0.6 \mathrm{~Hz} / \mathrm{s}$.

Considering an "inertialess penetration" of $50 \%$, the expected ratio between the synchronized kinetic energy of the system $E_{k}$ (in MWs) and the load level $P_{\text {load }}$ (in $\mathrm{MW}$ ) is around 6 seconds, and this is, therefore, the inertia constant of the conventional synchronized generation. For a $P_{\text {load }}=1000 \mathrm{MW}$, the installed capacity of wind facilities becomes $P_{w p p}=50 \% \cdot P_{\text {load }}=500 \mathrm{MW}$.

Finally, the largest severity of the power imbalance in the network model has to be determined for the analysis performed in the present study. For doing that, and according to [24], the so-called "operational metric 2" is defined. This magnitude is the ratio of kinetic energy stored in conventional generators plus load and the largest severity of the power imbalance. This ratio can be intended as an indicator of frequency stability. Stable operation of the 2020 scenario in the Irish network is considered with an "operational metric 2" greater than 20-30 MWs/MW. Considering that the kinetic energy stored in conventional generators is $E_{k}=1000 M W \cdot 6 s=6000 \mathrm{MWs}$, the largest severity of power imbalance is $P_{i m b}=\frac{6000 \mathrm{MWs}}{30 \mathrm{MWs} / \mathrm{MW}}=$ 200MW.

The flywheel-based storage system is sized so that it has twice the power and energy capacity of a storage plant the manufacturer of flywheels Beacon Power has commissioned for frequency regulation [25]. This system is able to continuously regulate $20 \mathrm{MW}$ for 15 minutes at full load, extending its operation for lesser loads. The storage plant proposed in the present work is composed by 400 flywheel small units. Each unit can continuously regulate $100 \mathrm{~kW}$ for 15 minutes. Operated at partial load, one can come up with a storage plant that can continuously regulate $20 \mathrm{MW}$ for 30 minutes. All units are connected in parallel, as in the above mentioned commercial solution. A summary of the parameters for the network configuration is presented in Table 1.

The characteristic parameters of the particular model 


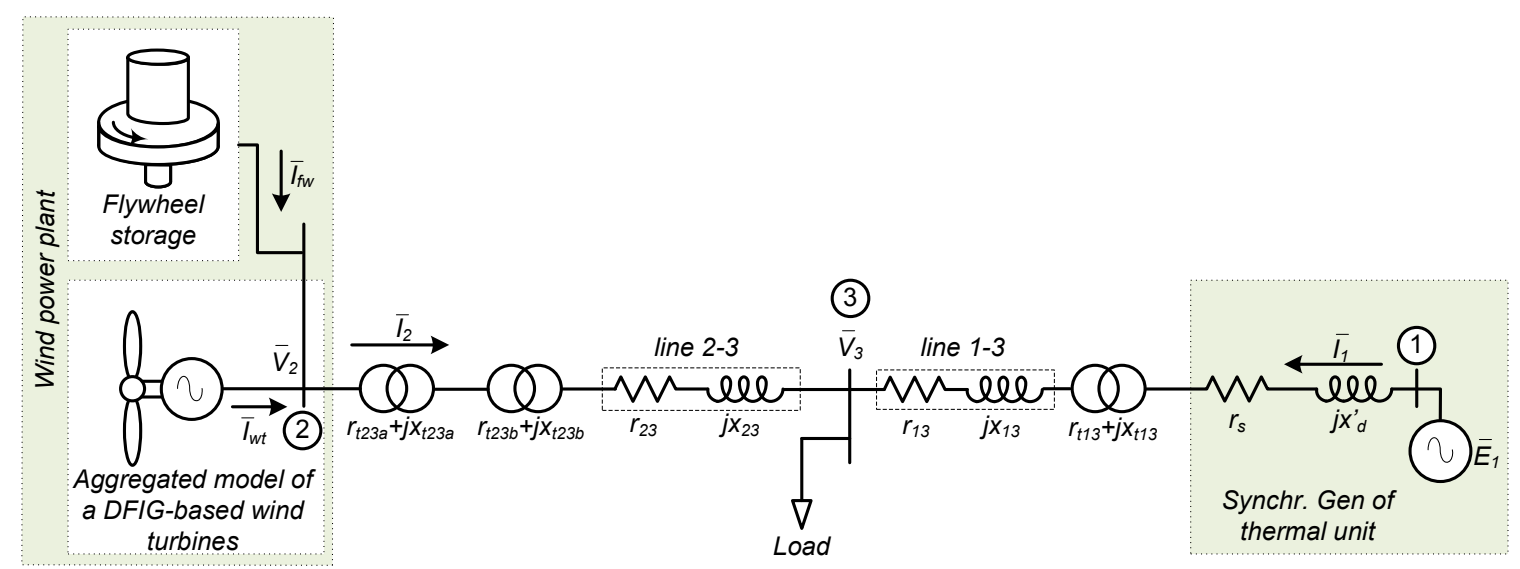

Figure 6: Network topology. The wind power plant is equipped with a flywheel-based storage system

Table 1: Parameters for the study case

\begin{tabular}{lll}
\hline Parameter & Value & Units \\
\hline $\begin{array}{l}\text { Rated power of conventional generation } \\
\text { Primary control droop of conv. genera- }\end{array}$ & 0.05 & $\mathrm{pu}$ \\
tion $R$ & & \\
Inertia constant of conventional genera- & 6.0 & $\mathrm{~s}$ \\
tion $H$ & & \\
Largest power imbalance in the network & 200.0 & $\mathrm{MVA}$ \\
Rated power of WPP & 500.0 & $\mathrm{MVA}$ \\
$\begin{array}{l}\text { Primary control droop of WPP } R_{w p p} \\
\text { Limits of } \Delta x \text { of primary control of WPP }\end{array}$ & 0.1 & $\mathrm{pu}$ \\
$\begin{array}{l}\text { Steady state power margin of WPP } x_{s d}^{*} \\
\text { Ratings of flywheel-based storage plant }\end{array}$ & 0.1 & $\mathrm{pu}$ \\
& & $\mathrm{pu}$ \\
& & $\mathrm{MW}-$ \\
Number of flywheel units $n_{f w}$ & 400 & $\mathrm{mu}$ \\
Maximum power consumption of the & 1200 & $\mathrm{MVA}$ \\
load & & \\
\hline
\end{tabular}
(200 MW) as defined in Section 3.1. The wind speed is maintained constant at $7.5 \mathrm{~m} / \mathrm{s}$.

As shown, since the wind speed is low, the rated rotor speed is not achieved even while derating the turbine. Therefore, the pitch angle is zero at all times and 

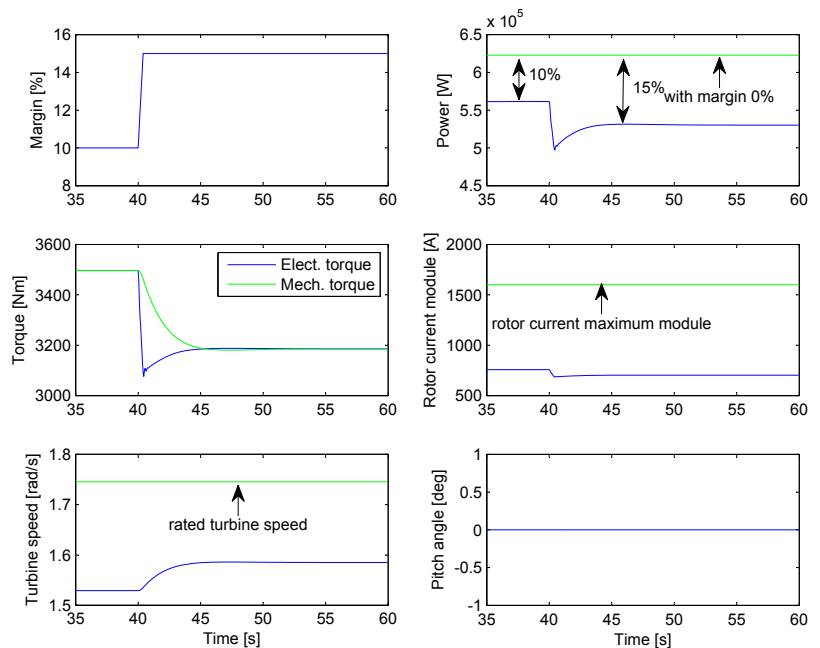

Figure 7: Performance evaluation of the proposed control system for deloaded operation. The power margin reference $x_{w t}^{*}$ is incremented from 0.10 to $0.15 \mathrm{pu}$. The wind turbine is subjected to a low wind speed of $7.5 \mathrm{~m} / \mathrm{s}$

the torque reference is obtained from the deloaded $T-\omega$ curves of Figure 2.

Figure 8 plots the response of the turbine on the same power margin increment. The wind speed is maintained constant at $8.5 \mathrm{~m} / \mathrm{s}$.

The wind speed is lower than the rated wind speed for the turbine $(10.1 \mathrm{~m} / \mathrm{s})$. However, the rated rotor speed of the turbine is achieved for a power margin $x_{w t}^{*}$ of 0.15 pu. From this point on the pitch angle is not zero and the torque reference is obtained from the second look-uptable (see Figure 3), which inputs the pitch angle and the required power margin. It is worth noting that the turbine speed is maintained within its operating limits due to the combined regulations of the electrical torque and the pitch angle. The temporal response of the speed of the turbine presents just a little overshot between 40 and 41 seconds. The peak value of the rotor speed during this overshot overpasses in just $0.4 \%$ the rated rotor speed.

The primary frequency control support that the wind turbines can provide is evaluated in Figure 9. Neither the flywheels, nor other control schemes apart from the control scheme for deloading the wind turbines (Figure 4) is applied.

A step increase in the load of $200 \mathrm{MW}$ is applied to
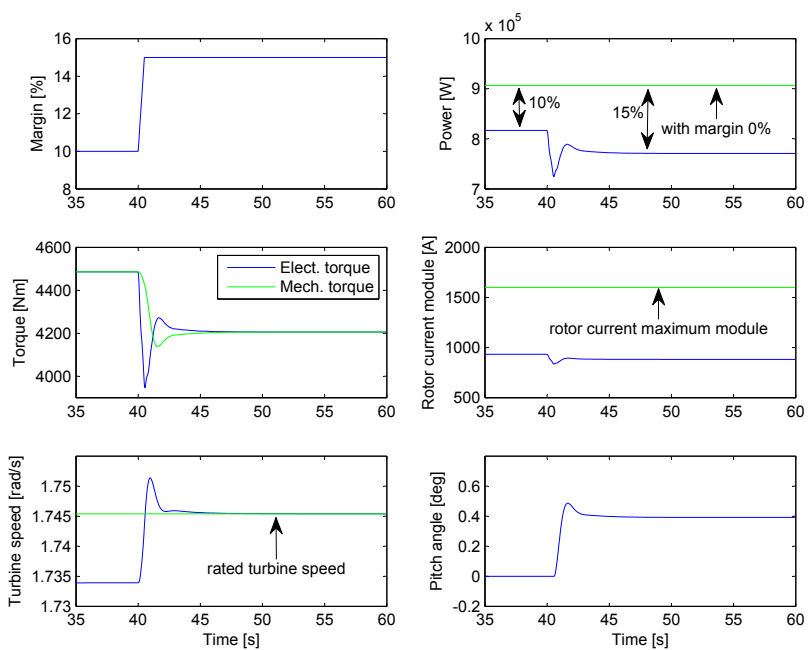

Figure 8: Performance evaluation of the proposed control system for deloaded operation. The power margin reference $x_{w t}^{*}$ is incremented from 0.10 to $0.15 \mathrm{pu}$. The wind turbine is subjected to a low wind speed of $8.5 \mathrm{~m} / \mathrm{s}$

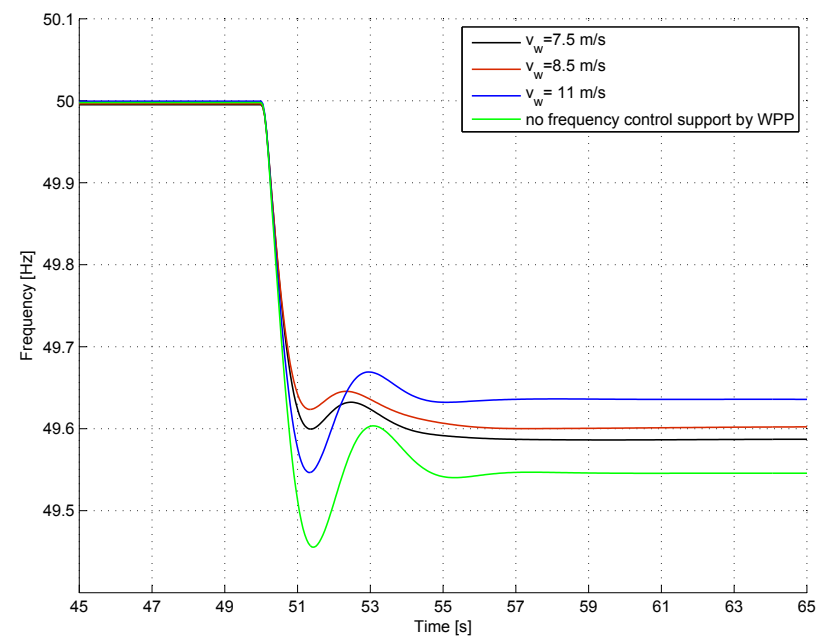

Figure 9: Network frequency excursion due to a sudden change in the load level of $200 \mathrm{MW}$. Wind turbines participate in primary frequency control under different load conditions. The flywheels are not involved 
the system, which provokes a network frequency disturbance. As can be noted, the maximum rate of change of frequency (registered at the beginning of the disturbance) is the same in all cases as the synchronized inertia of the system does not vary. Considering wind speeds below the rated $(7.5 \mathrm{~m} / \mathrm{s}$ and $8.5 \mathrm{~m} / \mathrm{s})$, both the frequency nadir and the steady state level of the frequency after the disturbance are improved with the participation of wind turbines in primary frequency support. In this region, the regulation of the power margin maintained by the wind turbines is mainly carried out by overspeeding the turbines. As previously noted in Figure 7 and Figure 8 this regulation is very fast and also implies the exchange of kinetic energy of the rotor of the turbines with the network. These aspects favours the provided primary frequency support to the network.

Considering wind speeds above rated (blue line in Figure 9), the power regulation of the wind turbines is influenced by the dynamics of the pitch control. These dynamics are much slower than those involved in overspeeding techniques. Also, since the rotational speed of the turbines is kept constant, there is no kinetic energy of the rotor of the turbines exchanged with the network. These aspects lead a lower frequency nadir than applying overspeeding techniques. On the other hand, since a variation in the power margin reference of the turbines $\Delta x$ implies the regulation of high power, the new steady state frequency level achieved after the network disturbance is much higher than in the case of considering low wind speed levels.

\subsection{Coordinated activation of the power reserves of the wind turbines and the flywheels under a network dis- turbance}

The following set of simulations concerns the coordinated regulation of the power margin developed by the components within the WPP, i.e. the wind turbines and the flywheels, so that it can fulfil the power margin requirements set by the network operator in steady state conditions and also during a network disturbance.

This coordinated regulation of the power margin developed by the components of the WPP is carried out by the central control system of the WPP and the local controllers of the wind turbines and the flywheels (Figure 5).

In order to evaluate the performance of the proposed control systems under different load conditions of the wind turbines, two wind speed levels have been considered. Firstly, a wind speed level low enough to permit the wind turbines to fulfil their power margin reference $x_{w t}^{*}$ by just applying overspeeding techniques is considered. Secondly, a wind speed level above the rated so the required power margin of the wind turbines is governed by their pitch control is applied. Additionally, a third analysis concerning variable wind speed is included, in order to evaluate the performance of the controllers under realistic operating conditions.

\subsubsection{Low wind speed level}

As in the previous simulations, a sudden power imbalance in the network which the generating units of the system (both the conventional generating unit and the WPP) have to compensate through their primary frequency controllers is considered.

Figure 10 plots the total power margin developed by the WPP. As a reminder, the total power margin for the WPP is determined from the sum of the steady state power margin reference for the WPP $x_{s d}^{*}$ and the power margin increment or decrement set by the primary control droop $\Delta x$. As can be noted in Figure 10, at time 60 seconds a sudden system load increase is considered. This provokes the system frequency to drop to a level below 50 $\mathrm{Hz}$, and therefore the WPP is required to reduce the developed power margin, i.e. to increase its power injection to the grid. The steady state power margin reference for the WPP is set to $x_{s d}^{*}=0.10$ with respect to the maximum available power that could be extracted from wind.

The required power margin is provided by the power reserves of the wind turbines and the energy stored in the flywheels. The variation of the power margin of the wind turbines is carried out as soon as the primary control droop of the local controllers of the wind turbines output an increment or decrement power margin variation $\Delta x$ greater than the power margin the storage facility can handle. This can be appreciated in Figure 11.

As can be observed, the developed power margin by the wind turbines previous to the network disturbance is about $x_{w t}=0.034 \mathrm{pu}$. The total power margin required by the system operator is $x_{s d}^{*}=0.10 \mathrm{pu}$. Thus, the storage facility, which State of Charge (SoC) is $100 \%$, is in charge of handling a power margin $x_{f w}=0.10-0.034=0.066 \mathrm{pu}$. The network disturbance provokes that the primary control droops of the local controllers of the flywheels and the 


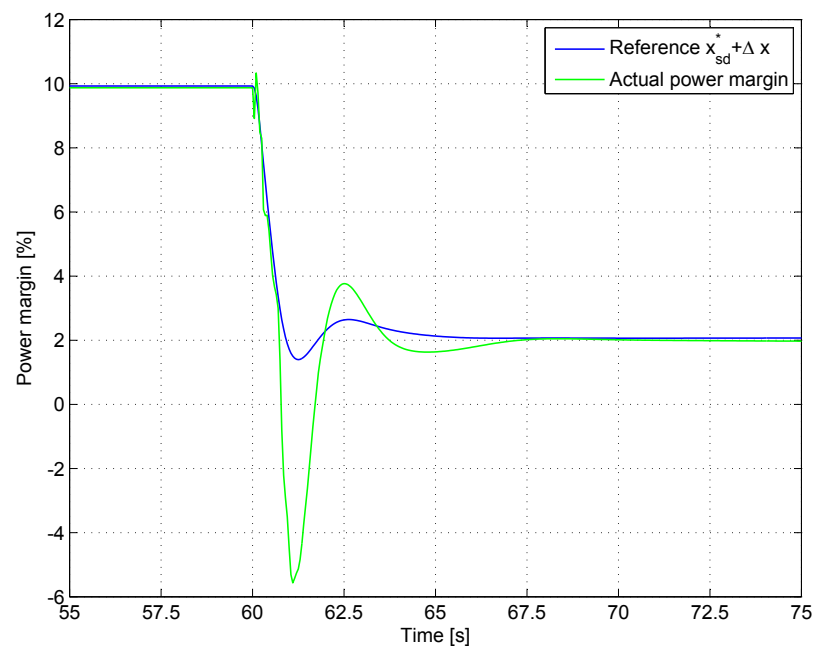

Figure 10: Power margin developed by the wind power plant. At time $\mathrm{t}=60$ seconds there is a sudden increase of the system load level. The wind turbines are exposed to a wind speed of $8.5 \mathrm{~m} / \mathrm{s}$

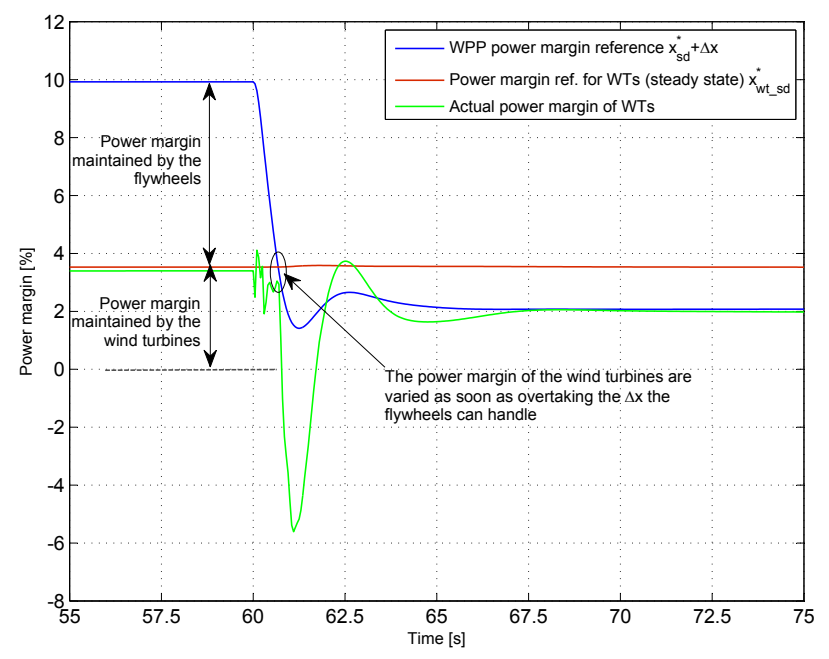

Figure 11: Power margin developed by the wind power plant. Detail of the power margin developed by the wind turbines and the flywheels. At 60 seconds simulation time there is a network disturbance. The wind turbines are exposed to a wind speed of $8.5 \mathrm{~m} / \mathrm{s}$ wind turbines output a decrement in the developed power margin $\Delta x$. Then, the total power margin reference for the WPP becomes $x_{s d}^{*}+\Delta x$. The regulation of the power reserves of the wind turbines is carried out as soon as the frequency deviation requires a decrement in the developed power margin greater than the maximum power margin the storage facility can handle $x_{c a p+}$.

As presented in Figure 11, the actual power margin developed by wind turbines does not follow the power margin reference $x_{s d}^{*}+\Delta x$ during the transient state provoked by the network disturbance, until achieving the new steady state. This is due to the fact that since the operating points of the wind turbines require applying just overspeeding techniques, there is kinetic energy released to the network from the speed regulation of the wind turbines. This surplus of energy released during the transient state complements the primary frequency support provided by the WPP.

To evaluate the provided frequency control support, Figure 12 plots the frequency excursion of the network. The red line plots the case of no frequency control support by the WPP. Only conventional synchronized generating units are in charge of developing this task therefore. With the participation of the WPP (the flywheels are fully charged), the obtained frequency profile is depicted by the blue line. As can be noted, higher frequency nadir and also higher frequency level at the new steady state after the disturbance can be obtained in this case.

As can be observed in Figure 12, the contribution of the WPP in primary frequency control depends on the SoC of the flywheels. Considering the flywheels discharged, i.e. leaving the wind turbines alone for carrying out the task, it can be obtained a higher frequency nadir than in the case the flywheels are also participating. This is due to the fact that in this case, the power margin of the wind turbines is regulated by just applying overspeeding techniques. Thus, some kinetic energy of the rotor of the turbines is exchanged with the network from the variation of their rotational speeds. As previously noted in the article, this surplus of energy injected to the grid improves the performance of the provided primary frequency support. Therefore, if the flywheels are discharged, the wind turbines have to satisfy the net variation of the power margin requirements, and then they are speeded down in a higher extent than in the case the required power margin decrement is satisfied also by the flywheels, leading a higher 


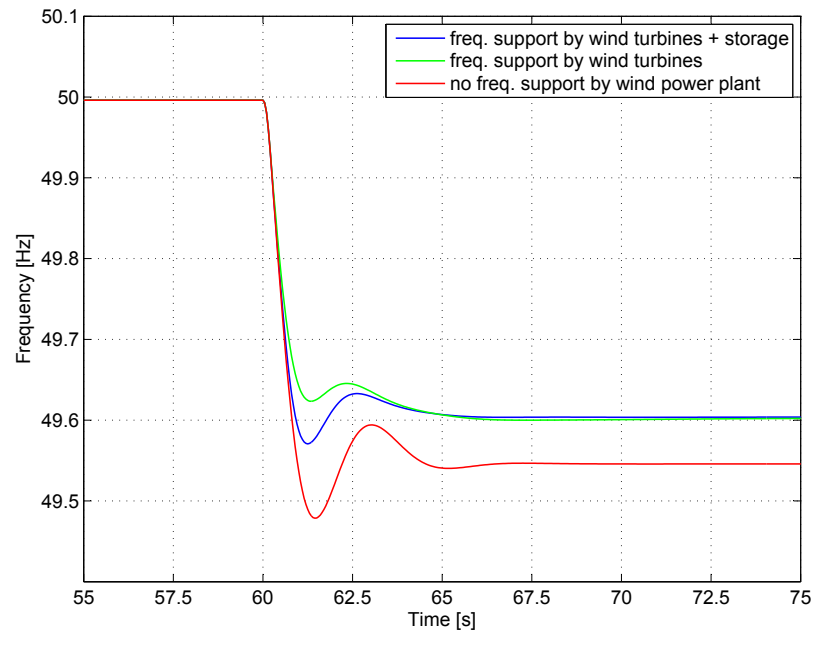

Figure 12: Frequency deviation caused by a sudden load increase. Red line plots the case of no frequency support by the wind power plant Blue line shows the obtained performance from the support of the wind power plant (wind turbines and flywheels). Green line presents the obtained result considering the flywheels discharged. The wind turbines are exposed to a wind speed of $8.5 \mathrm{~m} / \mathrm{s}$

kinetic energy exchanged with the network.

\subsubsection{Wind speed above rated}

This section deals with the evaluation of the performance of the proposed controllers for the WPP while having wind speeds above the rated wind speed of the wind turbines. The wind speed level is set to $11 \mathrm{~m} / \mathrm{s}$ (the rated wind speed is $10.1 \mathrm{~m} / \mathrm{s}$ ) and the flywheels are fully charged. Figure 13 plots the power margin developed by the WPP while having a network disturbance.

As can be noted in Figure 13, the developed power margin by the WPP follows the reference $x_{s d}^{*}+\Delta x$ to a large degree. From a certain point the developed power margin is transiently different from the reference level. At the beginning of the frequency deviation, the flywheel storage activates very fast its power reserves, so the developed power margin matches with the reference. This occurs until the regulation of the power margin of the wind turbines comes into play. Since the regulation of the power margin of the wind turbines depends, in this case, on the slow dynamics of their pitch actuator, the regulation of the power margin is not fast enough to follow the reference during the transient state.

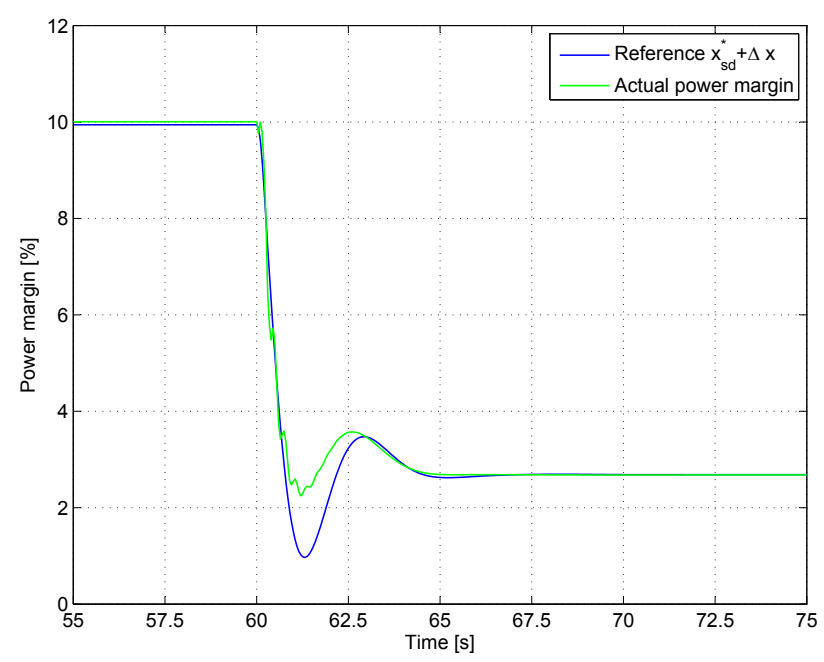

Figure 13: Actual power margin developed by the wind power plant and its reference value $x_{s d}^{*}+\Delta x$. The wind speed is $11 \mathrm{~m} / \mathrm{s}$

The dynamics of the pitch actuator of a wind turbine are shown in Figure 14 (bottom left corner). Figure 14 also plots the speed and torque of the turbine. As shown the turbine speed is varied in a very little extent. Moreover, the speed of a flywheel is presented in the top left corner. As shown, the flywheel starts injecting power into the grid as soon as detecting the frequency variation due to the network disturbance. As a result, its SoC, i.e. its rotational speed becomes continuously reduced. However, it is important to note that there are no fast changes in the speed of the flywheel, which favours the slow dynamics of the control signals $x_{\text {cap }+}, x_{\text {cap- }-}, P_{\text {cap }+}$ and $P_{\text {cap }-}$. Finally, it is worth noting the continuous (but slowly) discharging of the flywheel prior to the network disturbance. This is due to the standing losses of the storage device. An strategy for maintaining a particular SoC of the flywheels in steady state conditions is required for ensuring the optimal operation of the storage devices. The determination of this optimal SoC depends on the cost associated to the losses of the flywheels among other aspects. This defines an optimization problem which is out of the scope of the article.

Figure 15 plots the frequency excursion due to the network disturbance at 60 seconds simulation time. The red line plots the case of no frequency control support by the WPP. Only conventional generating units are in charge of 

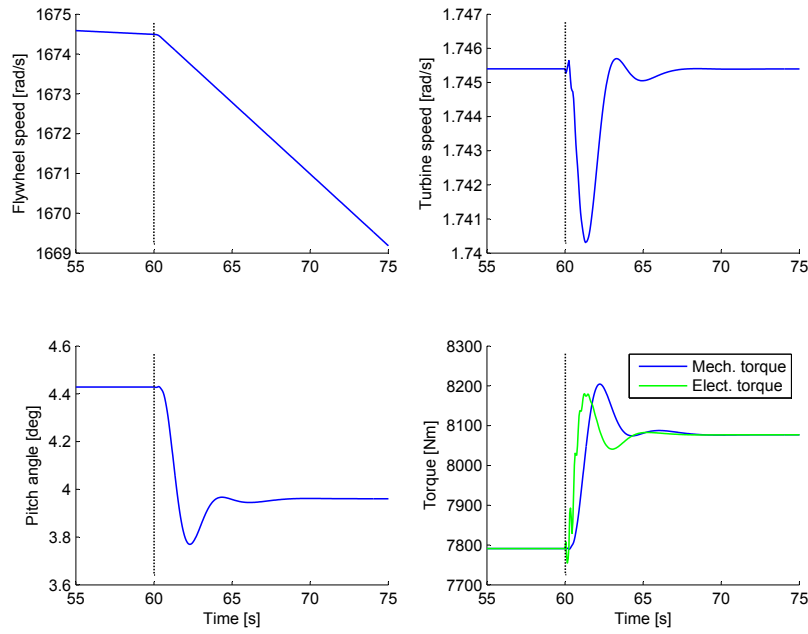

Figure 14: Flywheel speed before and after detecting the network disturbance at time 60 seconds. Also, it is shown the speed, the pitch angle and the mechanical and electrical torque developed by wind turbines. The wind turbines are exposed to a wind speed of $11 \mathrm{~m} / \mathrm{s}$

this task in this case. With the participation in primary frequency control of the WPP (the flywheels are charged) the obtained frequency excursion is depicted by the blue line. As can be noted, the contribution of the wind turbines and the flywheels improve the obtained frequency nadir and also the new steady state after the disturbance.

Figure 15 also plots the case of considering the flywheels discharged. The primary frequency control support the wind turbines can provide in this case (their power margin is affected by the dynamics of the pitch actuator) is as good as the support provided by the WPP when considering the fast actuation of the flywheels. This is due to the fact that despite the flywheels responds in the range of milliseconds to a power request, its power injection is governed by the slow dynamics imposed by the output of the primary control droop of its local control system, i.e. the slow dynamics of the frequency excursion.

From the analysis performed in this Section 3.3, it is worth to remark that the main advantage of including the flywheels in the WPP is the reduction of the power margin that the wind turbines have to maintain during network disturbances and also in steady state conditions. In this regard, Table 2 depicts the assignment of the required power reserve to the WPP between the flywheels and the

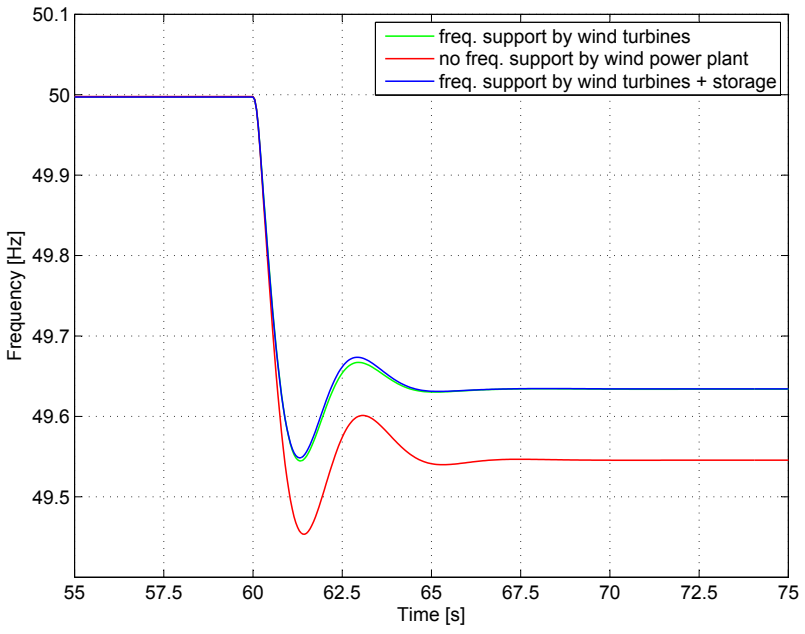

Figure 15: Frequency deviation caused network disturbance. Red line plots the case of no frequency support by the wind power plant. Blue line shows the obtained performance from the contribution of the wind power plant (wind turbines and flywheels). Green line presents the result considering the flywheels discharged. The wind turbines are exposed to a wind speed of $11 \mathrm{~m} / \mathrm{s}$

wind turbines. As it can be noted, the flywheels, while being fully charged, are capable of providing up to the net level of power reserves of the WPP depending on the wind speed, enabling the wind turbines to operate at maximum efficiency in a continuous basis (as for $7.0 \mathrm{~m} / \mathrm{s}$ wind speed).

\subsubsection{Variable wind speed}

Previous sections, by considering constant wind speed for the WPP, permitted to clearly evaluate how the designed control system works, while also serving as illustrative examples for the understanding of magnitudes such as the previously presented power margin. This section goes a step forward and shows the performance of the designed control system under realistic wind speed conditions. For the sake of completeness, the electrical load installed at bus 3 (see Figure 6) also presents a time varying demand profile, noticeably disrupting the constancy of the electrical frequency of the network.

The adopted wind model is explained and utilised in previous work of the authors of the present article [28]. This model is adopted here to represent the wind speed the WPP is exposed to. It comprises a quasi-constant av- 
Table 2: Power reserve allocation between wind turbines and flywheels (fully charged)

\begin{tabular}{|c|c|c|c|c|c|}
\hline & \multicolumn{5}{|c|}{ Wind speed $(\mathrm{m} / \mathrm{s})$} \\
\hline & 7.0 & 8.0 & 9.0 & 10.0 & 11.0 \\
\hline & \multicolumn{5}{|c|}{ Required reserve to the WPP in (MW) } \\
\hline & 16.7 & 25.3 & 35.9 & 49.2 & 50.7 \\
\hline & \multicolumn{5}{|c|}{ Power reserve allocation } \\
\hline W. turbines (MW) & 0.0 & 5.3 & 15.9 & 29.3 & 30.7 \\
\hline Flywheels (MW) & 20.0 & 20.0 & 20.0 & 20.0 & 20.0 \\
\hline $\begin{array}{l}\text { Flywheels share } \\
(\%)\end{array}$ & 120.0 & 79.3 & 55.7 & 40.7 & 39.5 \\
\hline
\end{tabular}

erage component (in the range of minutes) and a varying wind speed component, which depends on deterministic (wind shear, tower shadow, the presence of obstacles) and stochastic factors (wind turbulence). This model corresponds to the so-called "Effective wind model" and detailed explanations can be found in [29]. The quasiconstant average component of the wind corresponds to a varying average trend (in the range of minutes) that has been extracted from the NREL's online database for wind speeds [30]. In regard of the load demand, it is varied periodically in incremental and decremental steps of 200 MW so as to provoke, as a consequence of the induced transient power unbalance in the network, the electrical frequency to go under and above its nominal value.

Figure 16 graphically describes the above presented simulation scenario. The variable wind power profile corresponding to the above introduced time varying wind speed trend can be found in the upper subplot. The subplot in the middle depicts the time varying load demand. Altogether affect the electrical frequency of the network as represented in the subplot below, grey line. The variability of this frequency profile is diminished by the support provided by the WPP while compared to the case the WPP is not providing this, as depicted by the blue line.

The WPP is required to regulate its power reserves according to the above presented frequency variation. Figure 17 depicts the performance of the WPP controllers to continuously adjust the output of the installation so as to track the total power margin reference $x_{s d}^{*}+\Delta x$ (as a reminder, this reference is given by the sum of the steady state power margin reference for the WPP and the power
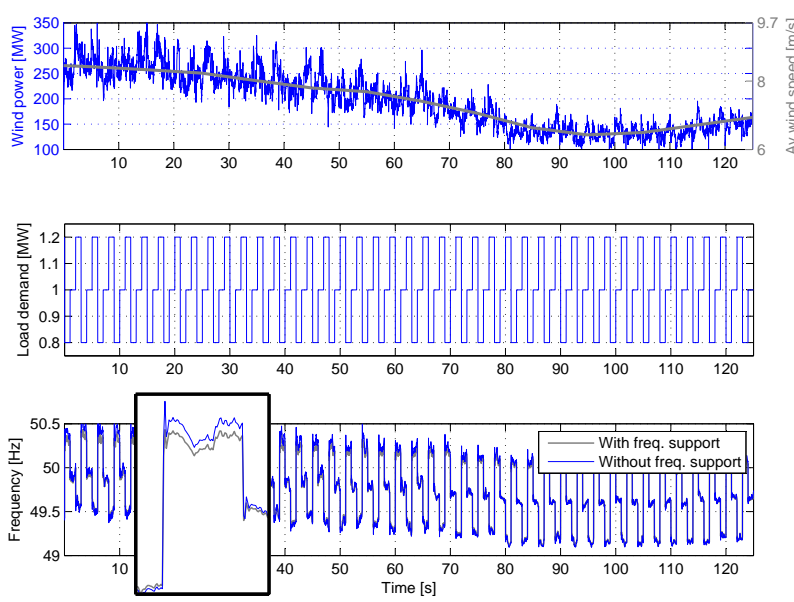

Figure 16: Time varying profiles for wind power and load demand, affecting the electrical frequency

margin increment or decrement set by the primary control droop). As can be noted, the actual power margin of the WPP successfully tracks the reference but presents cyclic spikes at the abrupt changes in frequency profile. As commented in previous sections of this article, these spikes are due to the surplus of energy injected or absorbed from the network while varying the kinetic energy of the wind turbines for power margin regulation through overspeeding techniques.

The total power margin developed by the WPP in steady state conditions $x_{s d}$ is the sum of the power margin provided by the flywheels (signal $x_{c a p+}$, proportional to the energy stored in the flywheels) and the power margin provided by the wind turbines $x_{w t . s d}$ (see Section 2.2). In order to satisfy the reference $x_{s d}^{*}$, the power margin of the wind turbines are varied depending on the state of charge of the flywheels and this distribution can be graphically evaluated in Figure 18. As can be noted, the power margin developed by the wind turbines (blue line) increases to compensate the decrement in the power margin that the flywheels can handle (green line) due to their progressive discharge associated to the standing losses. The resultant satisfies the power margin reference set by the network operator $x_{s d}^{*}=10$ (red line). 


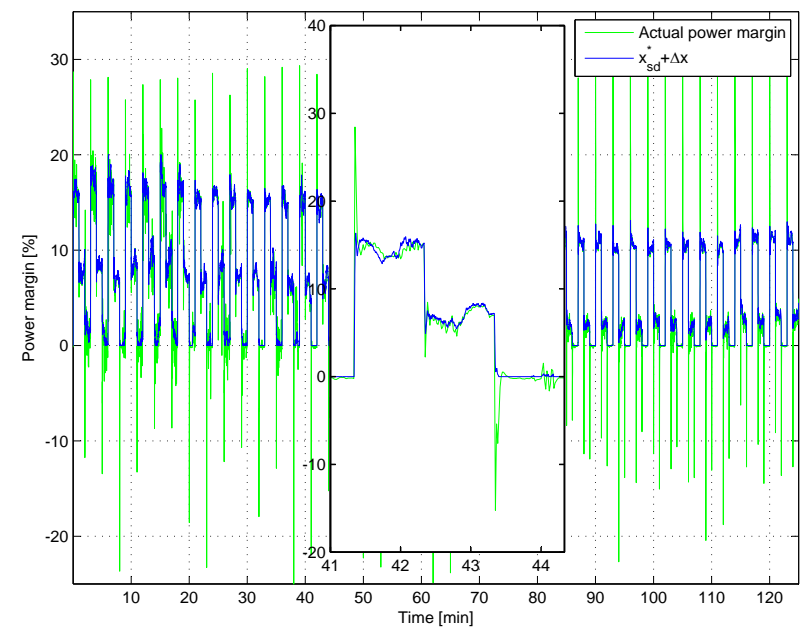

Figure 17: Power margin developed by the wind power plant under variable wind and load demand conditions.
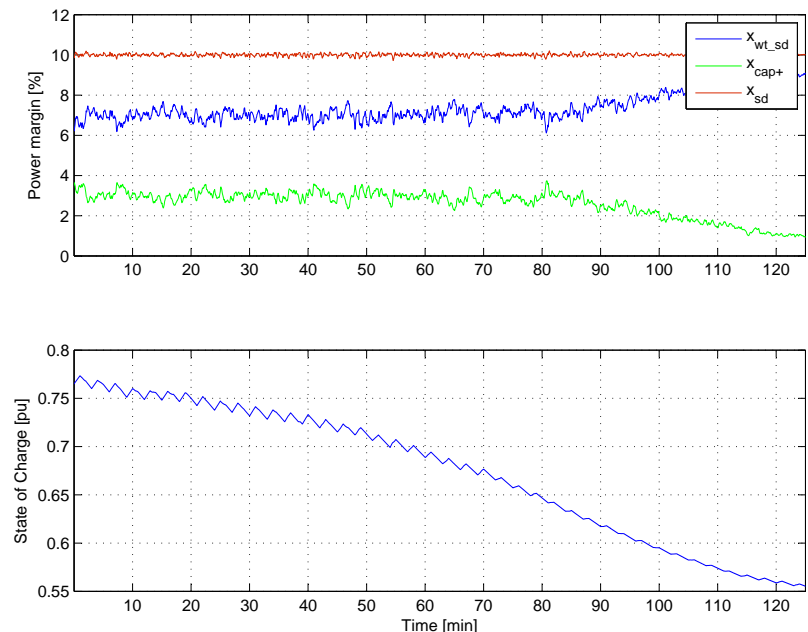

Figure 18: Time varying profiles for wind power and load demand, affecting the electrical frequency

\section{Conclusions}

The main conclusions of the presented work are outlined as follows:

- A control method for derating variable-speed wind turbines has been developed. This control method combines overspeeding techniques and pitching techniques. From the application of the designed method, the wind turbines can be operated so that they maintain a power margin from the maximum available power that can be extracted from wind. The method is applicable to all wind speed ranges of variable speed wind turbines; both above and below the rated wind speed level.

- The frequency control support that the wind turbines can provide permits to improve the frequency nadir and the steady state level of the frequency in case of a power unbalance in the network. The contribution of the wind turbines though, is subjected to the applied control techniques. For instance, in case of governing the power margin through overspeeding techniques, the frequency control support they can provide is augmented by the kinetic energy of the rotor of the turbine exchanged with the network due to the variation of their rotating speed.

- Looking at the contribution of the WPP to primary frequency control, it is worth noting that the application of the designed central control system of the WPP and the local controllers of the wind turbines and the flywheels, allow the management of the level of reserves maintained by the wind turbines in function of the SoC of the flywheels. The inclusion of the flywheels in the WPP reduces the need of operating the wind turbines in a deloaded mode, enabling them to operate extracting the maximum available power from the wind and thus maximizing the revenues of the WPP operator while still providing the primary frequency control support to the network.

\section{Acknowledgments}

This work was supported by KIC InnoEnergy SE under the project Smart Power and by the German Ministry for Environment, Nature Conservation and Nuclear Safety 
within the project "Wind park control for grid integration".

\section{Appendix}

The characteristic parameters of the synchronous generator of the conventional power plant are extracted from [21] (in p.u. stator base): rated power $1000 \mathrm{MVA}$, rated stator line-to-line voltage $18 \mathrm{kV}, r_{s}=0.0033, x_{d}=1.65$, $x_{q}=1.57, x_{l s}=0.15, x_{d}^{\prime}=x_{q}^{\prime}=0.275, T_{d 0}^{\prime}=6.5 \mathrm{~s}$, $T_{q 0}^{\prime}=1.25 \mathrm{~s}$. The parameters of its speed governor are [21] (in p.u. stator base): $R=0.05, T_{G}=0.2 \mathrm{~s}$. The parameter of the non-reheat turbine is [21]: $T_{C H}=0.3 \mathrm{~s}$.

The characteristic parameters of the DFIG are [26]: rated mechanical power $1.5 \mathrm{MW}$, rated stator line-to-line voltage $690 \mathrm{~V}$, rated rotor speed $1750 \mathrm{rpm}, r_{s}=2.65 \mathrm{~m} \Omega$, $r_{r}^{\prime}=2.63 \mathrm{~m} \Omega, x_{l s}=0.053 \Omega, x_{l r}^{\prime}=0.042 \Omega, x_{m}=1.72$, poles $P=4$, inertia $J_{g}=100 \mathrm{~kg} \cdot \mathrm{m}^{2}$. The characteristic parameters of the turbine are: $R=41.7 \mathrm{~m}$, inertia $J_{t}=3 \cdot 10^{6} \mathrm{~kg} \cdot \mathrm{m}^{2}$, damping coefficient $D=7.5 \cdot 10^{5}$ $\mathrm{Nms} / \mathrm{rad}$, stiffness $k=12 \cdot 10^{7} \mathrm{Nm} / \mathrm{rad}$, gear-box ratio $N=105$, rated wind speed $v_{w}=10.1 \mathrm{~m} / \mathrm{s}$. The aerodynamic parameters are [27]: $c_{1}=0.73, c_{2}=151$, $c_{3}=0.58, c_{4}=0.0002, c_{5}=2.14, c_{6}=13.2, c_{7}=18.4$, $c_{8}=-0.02, c_{9}=-0.003$.

The characteristic parameters of a flywheel unit are [25]: rated power $100 \mathrm{~kW}$, operating speed limits $16-8$ $\mathrm{krpm}$, torque losses $T_{\text {loss }}=1.19 \mathrm{Nm}$, inertia $J_{f w}=86.4$ $\mathrm{kg} \cdot \mathrm{m}^{2}$.

The characteristic parameters (in per unit) of the power transformers of the system are [21]: copper losses $0.1 \%$ of rated power, short-circuit voltage $\varepsilon=0.15 \mathrm{pu}$, leakage reactance $0.1 \mathrm{pu}$. The particular ratings of each transformer are: ratings of the step-up power transformer for the voltage of the conventional generating unit $1000 \mathrm{MVA}-220$ $\mathrm{kV} / 18 \mathrm{kV}$; ratings of the step-up transformers for the voltage of the WPP 500 MVA - $220 \mathrm{kV} / 30 \mathrm{kV}$ and 500 MVA - $30 \mathrm{kV} / 690 \mathrm{~V}$.

The characteristic parameters of the lines are: $r_{13}=$ $r_{23}=0.0212 \Omega / \mathrm{km}, x_{13}=x_{23}=0.116 \Omega / \mathrm{km}$, length $=50$ $\mathrm{km}$.

\section{References}

[1] Díaz-González F, Sumper A, Gomis-Bellmunt O, Villafáfila-Robles R. A review of energy storage technologies for wind power applications. Renewable and Sustainable Energy Reviews 2012;16:2154-2171

[2] National Grid plc. The grid code, issue 4 revision 13 (2012). Available online: http://www.nationalgrid.com/uk/. Access date: 26/04/2013

[3] EirGrid. Eirgrid grid code version 4.0. Available online: http://www.eirgrid.com. Access date: 26/04/2013

[4] ENTSO-E. Entso-e network code for requirements for grid connection applicable to all generators. Available online: https://www.entsoe.eu/. Access date: $26 / 04 / 2013$

[5] Kayikci M, Milanovic J. Dynamic contribution of dfig-based wind plants to system frequency disturbances. IEEE Transactions on Power Systems 2009;24:859-867

[6] Yingcheng X, Nengling T. Review of contribution to frequency control through variable speed wind turbine. Renewable Energy 2011;11:1671-1677

[7] Lalor G, Mullane A, O’Malley M. Frequency control and wind turbine technologies. IEEE Transactions on Power Systems 2005;20:1905-1913

[8] Rahmat-Ullah T, Thiringer N, Karlsson D. Temporary primary frequency control support by variable speed wind turbines - potential and applications. IEEE Transactions on Power Systems 2008;23:601612

[9] Sumper A, Gomis-Bellmunt O, Sudria-Andreu A, Villafafila-Robles R, Rull-Duran J. Response of fixed speed wind turbines to system frequency disturbances. IEEE Transactions on Power Systems 2009;24:181-192

[10] Bolund B, Bernhoff H, Leijon M. Flywheel energy and power storage systems. Renewable \& Sustainable Energy Reviews 2007;11:235-24

[11] Yogi-Goswami D, Kreith F. Energy conversion CRC Press Taylor \& Francis Group, 2007 
[12] Hadjipaschalis I, Poullikkas A, Efthimiou V. Overview of current and future energy storage technologies for electric power applications. Renewable and Sustainable Energy Reviews 2009;13:1513-10

[13] Moutis P, Papathanassiou S, Hatziargyriou N. Improved load-frequency control contribution of variable speed variable pitch wind generators. Renewable Energy 2012;48:514-523

[14] Junyent-Ferré A, Gomis-Bellmunt O, Sumper A, Sala M, Mata M. Modeling and control of the doubly fed induction generator wind turbine. Simulation Modeling Practice and Theory 2010;18:136581

[15] de Almeida R, Pecas-Lopes J. Participations of doubly fed induction wind generators in system frequency regulation. IEEE Transactions on power systems 2007;22:944-950

[16] Zertek G, Verbic A, Pantos M. Optimised control approach for frequency-control contribution of variable speed wind turbines. IET Renewable Power Generation 2012;6:17-23

[17] Zertek G, Verbic A, Pantos M. A novel strategy for variable-speed wind turbines' participation in primary frequency control. IEEE Transactions on Sustainable Energy 2012. Article in press

[18] Ramtharan J, Ekanayake G, Jenkins N. Frequency support from doubly fed induction generator wind turbines. IET Renewable Power Generation 2007;1:3-9

[19] Zhang Z-S, Sun Y, Lin J, Li G-J. Coordinated frequency regulation by doubly fed induction generation-based wind power plants. IET Renewable Power Generation 2012;6:38-47

[20] Ong C-M. Dynamic simulation of electric machinery using Matlab / Simulink. Prentice Hall PTR, 1997

[21] Kundur P. Power system stability and control. Mc Grau-Hill Inc., 1993

[22] Junyent-Ferré A, Gomis-Bellmunt O, Sumper A, Sala M, Mata M. Modeling and control of the doubly fed induction generator wind turbine. Simulation Modelling Practice and Theory 2010;18:1365-1381
[23] Díaz-González F, Sumper A, Gomis-Bellmunt O, Villafáfila-Robles R. Modeling, control and experimental validation of a flywheel-based energy storage device. Journal of European Power Electronics 2013;13

[24] EirGrid and System Operator for Northern Ireland (SONI). All island TSO facilitation of renewables studies. Available online: http://www.eirgrid.com. Access date: 26/04/2013

[25] Lazarewicz M. Status of flywheel storage operation of first frequency regulation plants. Beacon Power Corporation, Tech. Rep., 2011

[26] Wu B, Lang Y, Zargari N, Kouro S. Power conversion and control of wind energy systems. John Wiley \& Sons Inc, 2011

[27] Ackermann T. Wind power in power system. John Wiley and Sons Ltd. 2005.

[28] Díaz-González F, Sumper A, Gomis-Bellmunt O, Bianchi F.D. Energy management of flywheel-based energy storage device for wind power smoothing. Applied Energy 2013;110:207-219

[29] Bianchi FD, De Batista H, Mantz RJ. Wind turbine control systems. Principles, modeling and gain scheduling design. Springer; 2007

[30] National Renewable Energy Laboratory webpage: http://www.nrel.gov/. Access data: 15/10/2014 